\title{
INEQUALITIES FOR A POLYNOMIAL AND ITS DERIVATIVE
}

\author{
ABDUl AZIZ AND B. A. ZARGAR
}

Abstract. Let $P(z)$ be a polynomial of degree $n$ and $P^{\prime}(z)$ its derivative. In this paper we shall obtain certain sharp generalization of some results of Govil, Malik and P. Turān concerning the maximum modulus of $P(z)$ and $P^{\prime}(z)$.

\section{Mathematics subject classification (1991): 30A06, 30A64.}

Key words and phrases: Bernstein inequality, polynomials, derivative.

\section{REFERENCES}

[1] A. AZIZ AND Q. M. DAwood, Inequalities for polynomial and its derivative, J. Approx. Theory $\mathbf{5 4}$ (1988), 306-313.

[2] M. BIDKHAM AND K. K. DEwAn, Inequalities for polynomial and its derivative, J. Math. Anal. Appl. 166 (1992), 319-324.

[3] T. N. Chan AND M. A. Malik, On Erdös-Lax theorem, Proc. Indian Acad. Sci. 92 (1983), 191-193.

[4] N. K. GoviL, On the maximum modulus of polynomials, J. Math. Anal. Appl. 112 (1985), 253-258.

[5] V. K. JAIN, On the maximum modulus of polynomials with zeros outside a circle, Glasnik matematički 29(49) (1994), 267-274.

[6] P. D. LAX, Proof of a conjecture of P. Erdös on the derivative of a polynomial, Bull. Amer. Math. Soc. 50 (1944), 509-513.

7] M. A. MALIK, On the derivative of polynomial, J. London. Math. Soc 1 (1969), 57-60.

[8] T. J. Rivlin, On the maximum modulus of polynomials, Amer. math. monthly 67 (1960), 251-253.

[9] P. TURĀN, Über die Ableitung fon polynomen, Compositio Math. 7 ((1939-40)), 89-95.

[10] A. C. SCHAFFER, Inequalities of A. Markoff and E. Bernstein for polynomials and related functions, Bull. Amer. Math. Soc. 47 (1941), 565-579.

[11] R. S. VARGA, A comparison of the successive over relation method and semi-iterative methods using Chebyshev polynomials, J. Soc. Indust. Appl. Math. 5 (1957), 44. 